\title{
Development and testing of a new electronic foot health promotion programme on nurses' foot self-care
}

\author{
Minna Stolt ${ }^{1 *}$, Jouko Katajisto ${ }^{2}$, Johanna Peltonen ${ }^{3}$, Riitta Suhonen ${ }^{4}$ and Helena Leino-Kilpi ${ }^{1}$
}

\begin{abstract}
Background: Nurses form the largest professional group in health care, and they spend most of their working day on their feet. From the perspective of work well-being, healthy feet are important to tolerate the physical demands of nursing work. However, little is known about how nurses' foot self-care practices can be promoted with computerised interventions. The aim of this study was two-fold: to explore the preliminary effects of the electronic Foot Health Promotion Programme (FHPP) on foot self-care in nurses and to examine the usability of the programme.
\end{abstract}

Methods: A single group pretest-posttest design was used. The FHPP was targeted at nurses working in the operating theatre. The FHPP lasted for 4 weeks and focused on improving nurses' knowledge and awareness of foot self-care through self-directed learning tasks. The primary outcome was knowledge of foot self-care. The secondary outcomes were foot health and work ability. Thirty-seven participants completed the study. The outcomes were assessed at baseline (April-June 2017) and 4 weeks (August-September 2017) after the intervention ended. The data were analysed statistically.

Results: Participants' knowledge of foot self-care and foot health improved; however, the changes were not statistically significant. The FHPP was considered to be usable and has potential as a tool to increase knowledge of foot self-care among nurses.

Conclusions: The FHPP developed in this study is a newly developed potential tool to increase nurses' knowledge of foot self-care. Application of the FHPP as part of occupational health care may enhance nursing personnel's foot self-care and lower extremity health.

Trial registration: ClinicalTrials.gov NCT03116451, 17.4.2017.

Keywords: Foot health, Foot self-care, Intervention, Nurses, Work ability

\section{Background}

Foot self-care (caring for one's own feet) is important for maintaining and improving foot health and, in turn, general health. Foot health is one aspect of physical health. Physical health and its promotion are emphasised

\footnotetext{
*Correspondence: minna.stolt@utu.fi

'Department of Nursing Science, University of Turku, and Turku University Hospital, Turku, Finland

Full list of author information is available at the end of the article
}

in international strategies and guidelines $[1,2]$. However, in these guidelines, foot self-care and foot health are rarely mentioned as central enabling factors for physical health. Supporting foot self-care is commonly believed to be a prerequisite for maintaining and improving foot health; therefore, there is a need to include foot self-care in these guidelines.

Foot health is important throughout life. In general, foot health is appreciated, and attitudes towards the care 
of foot problems are often positive [3]. However, foot problems are common in working life among nurses [4] and can decrease quality of life, particularly among females [5]. Nurses form the largest professional group in health care. Nursing is physically demanding, including situations in which nurses' feet are exposed to stress for long periods in their daily work environment. However, studies focusing on supporting and improving nurses' foot health are limited [4].

Foot self-care is performed by individuals. It requires knowledge of how to look after oneself properly and practical skills in caring for one's own feet. Foot self-care involves regular hygiene, toenail and skin care, foot exercises and the use of appropriate footwear and socks [6]. Despite its rather straightforward content, foot self-care is often overlooked. Reasons for this may include lack of knowledge [7]; physical restrictions, such as arthritis [8] or obesity [9]; lack of motivation [10]; or the perception that caring for the feet is not important [11]. On the other hand, social support, foot-related education and communication between patients and providers have been reported to enable foot self-care [12].

Interventions focusing on foot self-care are scarce [13], and previous studies have focused on improving foot self-care in patients with diabetes $[14,15]$. The interventions studied were all educational, and they included key areas of diabetic foot self-care. Educational interventions were provided in groups [16-18] and in face-to-face settings $[16,17]$. They were reinforced by written material [14], lectures and meetings with health-care professionals $[14,19]$ or periodic support and foot checks [20]. The individual sessions varied from $20 \mathrm{~min}$ [21] to 90 $\mathrm{min}$ [16], and the full interventions lasted from $20 \mathrm{~min}$ [21] to 4 weeks [14]. Only a limited number of interventions were conducted in an electronic format, which included text messages [22] and audio-visual lectures [16]. These interventions resulted in improved knowledge of foot self-care, which confirms that foot self-care can be enhanced through an educational approach. However, there is limited evidence of how foot self-care can be improved through electronic programmes in occupational health settings, specifically among nurses.

Previous studies of foot self-care have focused on patients with long-term health problems [19]. However, litthe is known about foot self-care in professionals whose feet are exposed to stress for long periods in their daily work environment. One such group is nurses. In health care, nurses form the largest professional group [23], and they have higher rates of musculoskeletal disorders (MSDs) than people in all other occupations [24, 25]. Nurses spend most of their working day on their feet, often standing and walking on concrete or other hard surfaces. In clinical nursing practice, nurses need to stand and walk for long periods; it is estimated that nurses walk 4 to 5 miles in a 12-h shift [26]. All these factors increase the number of musculoskeletal disorders in nurses [27]. Nurses working in the operating theatre have to stand for long durations, often in poorly fitting footwear, which poses a threat to foot health. Footwear for standing environments should be selected individually, and the corresponding nurses' foot health status and functionality of the footwear should match with the environment [28].

Previous prevalence studies of MSDs have found that the proportion of knee, ankle and foot disorders in nurses is high. The prevalence of MSDs ranges from 22.8 to $68.7 \%$ in knees and from 9.3 to $53.4 \%$ in ankles and feet. In addition, leg fatigue and foot discomfort are prevalent in nurses $[29,30]$. Health problems caused by maintaining an upright posture for long durations include plantar fasciitis, muscle fatigue, varicose veins [31] and oedema [32]. The intensity of foot pain in nurses is high [33], and this intercorrelates with increased age and higher body mass index [34]. Moreover, the use of footwear that does not support foot health has a negative impact on general wellbeing at work [35]. Nurses tend to wear shoes that have lost their structural integrity, which increases foot pain and other foot problems [34]. All these problems in the lower extremities could be prevented and controlled by appropriate foot self-care.

Some interventions to promote general health and work ability have been tested [36, 37]. Structured workshops and periodical forums for sharing best practices are feasible and potentially useful for reducing MSDs and risk factors for work-related injuries [36]. More specifically, ergonomic interventions [37, 38], workplace exercises [39] and procedures for handling and lifting patients $[40,41]$ are also effective in reducing rates of MSDs. However, these studies did not focus on health in the lower extremities or on foot self-care. Therefore, interventions focusing on improving nurses' foot self-care are needed.

The aim of this study was two-fold: to develop and explore the preliminary effects of the electronic Foot Health Promotion Programme (FHPP) on foot self-care in nurses and to examine the usability of the programme. The research questions were as follows: 1) What effect does the FHPP have on knowledge of foot self-care, foot health and work ability? 2) What is the usability of the FHPP among nurses? The hypothesis was that the FHPP is effective in increasing knowledge of foot self-care.

\section{Methods/Design}

A single group pretest-posttest design was used. The trial was registered with ClinicalTrials.gov (identifier: NCT03116451). For the reporting of the results, the 
Transparent Reporting of Evaluations with Nonrandomized Designs (TREND) statement was followed [42].

The study was conducted in surgical units in one university hospital in Finland. All nurses working in these units were recruited to participate in the study. They received information about the study and, based on that, made the decision whether to participate or not. Nurses were eligible to participate if they 1 ) were a registered nurse; 2) had a permanent post in the hospital; 3) worked in the operating theatre; and 4) understood Finnish. A sample size of 60 was considered sufficient on the basis of a power analysis conducted using $\mathrm{NQu}$ ery 4.0 software using repeated-measures analysis of variance (ANOVA) with a two-sided 5\% significance level and a power of $80 \%$. A total of 60 eligible participants were recruited for the study; however, only 56 participated in the intervention. During the study period, 19 participants who had completed the baseline measurement (measurement 0 , later $\mathrm{M} 0$ ) withdrew from the research, which left 37 in the intervention group. Those who withdrew were not asked to give their reasons for doing so.

\section{Data collection}

The data were collected between 04/2017 and 09/2017. All the participants were assessed for baseline data (measurement 0) and follow-up data (measurement 1) within this time frame. Measurement 1 was performed 4 weeks after the intervention ended. In total, four instruments were used.

The primary outcome of knowledge of foot self-care was measured using the modified Foot Self-Care Knowledge Test [43]. The test consisted of 20 items divided into five subscales: skin care (4 items), toenail care (4 items), structural deformities in the foot (4 items), disease-specific foot problems (4 items), and footwear (4 items). The response options were "true," "false" and "do not know". The total score ranged from 0 to 20; the higher the score, the higher the level of knowledge about foot self-care.

The secondary outcomes were foot health and work ability. Foot health was measured using the Self-reported Foot Health Assessment Instrument (SFHAI). The S-FHAI is based on the clinical and objective Foot Health Assessment Instrument (FHAI) [44], which was modified to create a self-assessment form for this study. The S-FHAI consisted of 28 items divided into five subscales: skin health (12 items), toenail health ( 4 items), foot structure (5 items) and foot pain (7 items). The instrument produces a total sum variable (Foot Health Index) by totalling the items. The Foot Health Index ranges from 0 to 28; the higher the value, the healthier the feet. Work ability was measured by asking the participants to evaluate their current wellbeing at work on a scale from 0 to 10 . The higher the value, the better their work ability [45].

In addition, information was collected about the participants' age, gender, number of years and months working in health care, length of time working in their current unit and type of employment. Information was also gathered about the footwear worn at work and the importance of foot health in their current role.

The usability of the programme was evaluated by the participants 4 weeks after the intervention ended, at measurement 1 (August-September 2017), using a questionnaire developed for this study. The questionnaire consisted of 14 items. First, participants were asked to give the FHPP an overall rating (from 1 to 10 , where 1 is lowest and 10 is highest). Second, participants were asked 10 questions about the content and layout of the FHPP, to which they responded using a 5-point Likert scale $(1=$ strongly disagree, $5=$ strongly agree). Third, participants were asked three open-ended questions where they could freely express their feelings about the positive aspects of the FHPP, any concerns about the FHPP and any recommendations for future development.

\section{Intervention}

Interviews [10], a survey [46], a literature review [4] and collaboration with professionals in occupational health care guided the design and content of the educational electronic FHPP for nurses. The material in the FHPP covered foot self-care and the promotion of foot health. The content was divided into four topics: skin and toenail care, footwear and hosiery, foot structure and pain, and foot muscle strength (Table 1). A pretest to ensure the clarity of the FHPP was conducted with purposefully selected nurses $(n=6)$ working in the surgical units. They tested the FHPP and provided critical feedback about the clarity and understandability of the instructions and content. Based on the feedback, the wording of the instructions was revised, and some minor amendments were made to the content.

The intervention was delivered using the Moodle webbased learning environment. Each topic included lectures (delivered via Adobe Presenter), videos, photos and written material for self-directed learning. At the end of each theme section, the participants evaluated their learning by completing a knowledge test. The items in the knowledge test were related to the content of the topic, and the correct answers could be found in the material in Moodle. After completing the test, the participants received a list of the correct answers with feedback. The FHPP was available for 4 weeks. The participants used the FHPP independently, and they were able to move back and forth between the topics. 


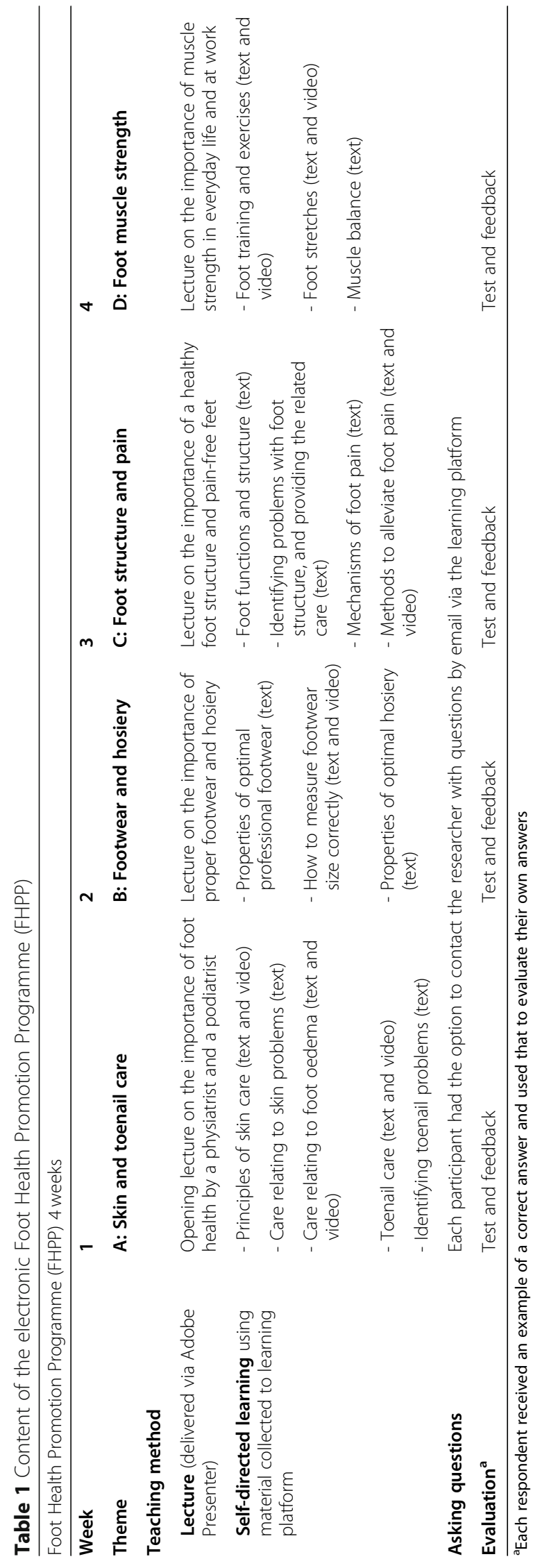




\section{Data analysis}

The data were analysed statistically using SPSS 22.0 software (SPSS Inc., Chicago, USA). The outcome data were analysed using descriptive statistics to describe the samples and study variables. Inferential statistics were used to test for differences between the groups; these statistics included ANOVA ( $F$ with degrees of freedom and $p$-value, for organisation comparisons and the non-parametric Kruskal-Wallis test). For longitudinal analyses, the general linear model (GLM, repeated measures) for continuous variables, the T-test (Mann-Whitney U-test) for analysis between groups, and the Wilcoxon signed rank test were used to analyse changes from baseline within groups. Multivariable methods, such as regression analysis and GLM statistics, were used to examine the hypothesised association between the variables. Factor analyses and structural equation modelling were used to examine the validity of the results. The psychometrics of the instruments were evaluated using the Kuder-Richardson formula.

The data on usability were analysed using descriptive statistics (frequency, percentage, mean, standard deviation and range) and inductive content analysis [47]. All phrases and sentences in the transcribed material that included terms or words close to those in the research questions were tabulated with the intent to organise the data. Using the identified sentences, responses to the research questions were collected. The units of meaning were condensed into smaller units, and those condensed units of meaning were abstracted and named using codes. Codes with similar properties were grouped together and named based on their content. The analysis process was confirmed by the research team.

\section{Ethical considerations}

The study was conducted in accordance with national legislation, general principles of research ethics [48] and national ethical standards [49]. Ethical approval was obtained from the university ethical review board (code: ETMK 14/2015, 23.2.2015), and permission to conduct the study was requested from the hospital in line with national standards and procedures. Each participant was informed in writing about the aim of the study; participants were also informed that their participation was voluntary, that their anonymity and confidentiality would be preserved in all phases of the study, and that they had the right to withdraw at any time without any negative consequences. Participants were also given the contact details of a member of the research team in case they wished to discuss the study in more detail. Written informed consent was obtained from each participant. To protect participants' privacy and anonymity, the data were coded using individual identifiers so that individual respondents could not be identified. The research data were stored on a server at the university. Permission to shorten and modify the Foot Self-Care Knowledge Test was obtained from the original developer.

\section{Results}

\section{Description of the study participants}

The mean age of the participants was 43.4 years (range 24-61), and the majority were female (95\%; see Table 2). Almost all participants considered foot health to be very important $(78 \%)$ or important $(16 \%)$ in their work. Three-quarters (73\%) of the participants said their work involved a great deal of standing or walking. One-third (35\%) of the participants had visited a physician due to foot problems, and one-fifth (19\%) had been on sick leave because of foot problems. Most of the participants believed that foot health had a large impact on their work $(60 \%)$.

\section{Effect of the FHPP on knowledge of foot self-care, foot health and work ability}

The primary outcome of the study was knowledge of foot self-care. Following the intervention, some improvement was achieved in the total score level for knowledge of foot self-care (Table 3). Therefore, overall, participants' knowledge increased following the intervention. However, the difference was not statistically significant $(p=0.126)$. At the individual level, $23 \%(n=13)$ of the participants improved their knowledge of foot self-care.

The secondary outcomes were foot health and work ability, and these improved slightly. The mean score on the Foot Health Index, which indicates the level of foot health, increased from 16.68 to 19.16 (Table 3); however, the difference was not statistically significant $(p=0.109)$. Some areas of foot health improved, but others worsened (Table 4). Instances of thickened toenails, colour changes in the toenails and hammer toes decreased considerably. On the other hand, instances of cold feet, low arches and oedema in the feet increased greatly. There were no significant differences in foot health at the item level. The intensity of foot pain increased in all areas of the foot; in particular, there was an increase in instances of strong pain in various areas of the foot when compared with the baseline data (Table 5). Pain in the thigh $(p=0.017)$ and pain in the heel $(p=0.003)$ increased significantly after the intervention. At the individual level, foot health improved in one-fifth of participants $(n=14,25 \%)$.

The participants' work ability decreased slightly following the intervention $(p=0.135)$. 
Table 2 Participant demographics $(n=37)$

\begin{tabular}{|c|c|c|c|c|}
\hline \multirow[t]{2}{*}{ Variable } & \multicolumn{4}{|c|}{ Intervention group (M0) } \\
\hline & $\bar{n}$ & Mean & range (SD) & $f(\%)^{\mathbf{a}}$ \\
\hline Age (years) & 35 & 43.43 & $24-61(10.30)$ & \\
\hline Practical experience in health care after graduation (years) & 37 & 20.10 & $2-42(10.80)$ & \\
\hline Practical experience in the current unit (years) & 36 & 11.51 & $1-31(7.97)$ & \\
\hline Gender & 36 & & & \\
\hline Male & & & & $1(3)$ \\
\hline Female & & & & $35(95)$ \\
\hline Importance of foot health at work & 35 & & & \\
\hline Very important & & & & $29(78)$ \\
\hline Important & & & & $6(16)$ \\
\hline Somewhat important & & & & $2(6)$ \\
\hline Amount of standing or walking at work & 37 & & & \\
\hline A lot & & & & $27(73)$ \\
\hline Quite a lot & & & & $9(24)$ \\
\hline Not much or a little & & & & $1(3)$ \\
\hline Visited a physician due to foot problems & 36 & & & \\
\hline Yes & & & & $13(35)$ \\
\hline No & & & & $23(62)$ \\
\hline Impact of foot health on work & 37 & & & \\
\hline Very large & & & & $22(60)$ \\
\hline Large & & & & $6(16)$ \\
\hline Neither large nor small & & & & $4(11)$ \\
\hline Small & & & & $3(8)$ \\
\hline Very small & & & & $2(5)$ \\
\hline Sickness absence due to foot problems & 37 & & & \\
\hline Yes & & & & $7(19)$ \\
\hline No & & & & $30(81)$ \\
\hline
\end{tabular}

athe number of responses vary due to missing information

\section{Usability of the FHPP}

The participants gave the FHPP a rating of 6.9 out of 10 (range 4-9). Overall, the participants evaluated the usability of the FHPP as positive. The participants thought that the instructions related to the FHPP were clear (mean 4.2) and that the whole programme was easy to use (mean 4.1). They thought the content of the FHPP was up to date (mean 3.9) and versatile (mean 3.8). The technical aspects of the FHPP worked well (mean 3.7), and it was considered beneficial (mean 3.6). The FHPP inspired participants to care for their feet (mean 3.3), and they felt that the layout was attractive (mean 3.0). The participants thought that the FHPP met their expectations (mean 3.5) and needs (mean 3.5).

Table 3 Participants' knowledge of foot self-care, foot health and work ability

\begin{tabular}{|c|c|c|c|c|c|}
\hline \multirow[t]{2}{*}{ Outcome } & \multicolumn{2}{|c|}{ Baseline $(\mathrm{M} 0) \boldsymbol{n}=37$} & \multicolumn{2}{|c|}{ Post-test (M1) $\boldsymbol{n}=37$} & \multirow[t]{2}{*}{$p$-value* } \\
\hline & Mean & Range & Mean & Range (SD) & \\
\hline \multicolumn{6}{|l|}{ Primary outcome: } \\
\hline Knowledge of foot self-care & 12.1 & $2-19(3.01)$ & 13.23 & $6-17(2.65)$ & 0.126 \\
\hline \multicolumn{6}{|l|}{ Secondary outcomes: } \\
\hline Foot Health Index & 16.68 & $10-32(5.40)$ & 19.16 & $9-36(6.82)$ & 0.109 \\
\hline Work ability & 8.78 & $6-10(1.16)$ & 8.27 & $4-10(1.49)$ & 0.135 \\
\hline
\end{tabular}

*T-test (Mann-Whitney U-test) 
Table 4 Participants' self-reported foot health (by item)

\begin{tabular}{|c|c|c|c|c|}
\hline \multirow[t]{2}{*}{ Variable } & \multicolumn{2}{|c|}{ Baseline (M0) $\boldsymbol{n}=37$} & \multicolumn{2}{|c|}{ Post-test (M1) $\boldsymbol{n}=37$} \\
\hline & $f$ & $\%$ & $f$ & $\%$ \\
\hline \multicolumn{5}{|l|}{ Skin healt } \\
\hline Skin breaks or macerations between toes & 4 & 14 & 3 & 8 \\
\hline Dry skin & 22 & 60 & 24 & 65 \\
\hline Heel fissures & 9 & 24 & 10 & 27 \\
\hline Corns or calluses & 14 & 38 & 19 & 51 \\
\hline Verrucae & 0 & 0 & 0 & 0 \\
\hline Blisters & 2 & 5 & 4 & 11 \\
\hline Oedema & 14 & 38 & 14 & 38 \\
\hline Sweating feet & 8 & 22 & 13 & 35 \\
\hline Burning feet & 6 & 16 & 6 & 16 \\
\hline Cold feet & 10 & 27 & 18 & 49 \\
\hline Leg cramps & 13 & 35 & 15 & 41 \\
\hline \multicolumn{5}{|l|}{ Toenail health } \\
\hline Ingrown toenail & 2 & 5 & 5 & 14 \\
\hline Thickened toenail & 8 & 22 & 6 & 16 \\
\hline Colour changes in the toenails & 10 & 27 & 6 & 16 \\
\hline Fungal infection of the toenails & 1 & 3 & 1 & 3 \\
\hline \multicolumn{5}{|l|}{ Foot structure } \\
\hline Hallux valgus & 10 & 27 & 10 & 27 \\
\hline Taylor's bunion & 5 & 14 & 7 & 19 \\
\hline Hammer toes & 1 & 3 & 0 & 0 \\
\hline Low arches & 8 & 22 & 16 & 43 \\
\hline High arches & 1 & 3 & 4 & 11 \\
\hline
\end{tabular}

The participants considered that overall, the FHPP is a suitable method for providing education about foot self-care. They were satisfied with the information and especially valued the education on footwear and socks and on strength in the lower muscles. However, they identified some areas for development. One theme of the FHPP was foot exercises, and the education on this was provided in the form of written instructions and videos, where a podiatrist demonstrated the exercises. The participants thought that foot exercises were important, but they were not sure whether they were performing the exercises correctly. Therefore, the participants suggested that foot exercises could be either supervised (with more detailed instructions) or guidance could be provided in faceto-face groups by a podiatrist.

Table 5 Foot pain in participants

\begin{tabular}{|c|c|c|c|c|c|c|c|c|c|c|c|c|c|c|c|c|c|c|c|c|}
\hline \multirow{3}{*}{$\begin{array}{l}\text { Location of } \\
\text { pain }\end{array}$} & \multicolumn{10}{|c|}{ Baseline (M0) $\boldsymbol{n}=37$} & \multicolumn{10}{|c|}{ Post-test (M1) $\boldsymbol{n}=37$} \\
\hline & \multicolumn{2}{|c|}{$\begin{array}{l}\text { No } \\
\text { pain }\end{array}$} & \multicolumn{2}{|c|}{$\begin{array}{l}\text { Slight } \\
\text { pain }\end{array}$} & \multicolumn{2}{|c|}{$\begin{array}{l}\text { Moderate } \\
\text { pain }\end{array}$} & \multicolumn{2}{|c|}{$\begin{array}{l}\text { Strong } \\
\text { pain }\end{array}$} & \multicolumn{2}{|c|}{$\begin{array}{l}\text { Worst imaginable } \\
\text { pain }\end{array}$} & \multicolumn{2}{|c|}{$\begin{array}{l}\text { No } \\
\text { pain }\end{array}$} & \multicolumn{2}{|c|}{$\begin{array}{l}\text { Slight } \\
\text { pain }\end{array}$} & \multicolumn{2}{|c|}{$\begin{array}{l}\text { Moderate } \\
\text { pain }\end{array}$} & \multicolumn{2}{|c|}{$\begin{array}{l}\text { Strong } \\
\text { pain }\end{array}$} & \multicolumn{2}{|c|}{$\begin{array}{l}\text { Worst imaginable } \\
\text { pain }\end{array}$} \\
\hline & $f$ & $\%$ & $f$ & $\%$ & $f$ & $\%$ & $f$ & $\%$ & $f$ & $\%$ & $f$ & $\%$ & $f$ & $\%$ & $f$ & $\%$ & $f$ & $\%$ & $f$ & $\%$ \\
\hline Toes & 39 & 70 & 4 & 11 & 3 & 9 & 5 & 9 & 1 & 3 & 24 & 65 & 5 & 14 & 2 & 5 & 5 & 14 & 1 & 3 \\
\hline Sole of the foot & 18 & 49 & 6 & 16 & 9 & 24 & 4 & 11 & 0 & 0 & 15 & 41 & 11 & 30 & 5 & 14 & 4 & 11 & 1 & 3 \\
\hline Heel & 26 & 70 & 5 & 14 & 4 & 11 & 1 & 3 & 1 & 2 & 19 & 51 & 6 & 16 & 6 & 16 & 6 & 16 & 0 & 0 \\
\hline Ankle & 25 & 68 & 5 & 14 & 5 & 14 & 2 & 5 & 0 & 0 & 22 & 60 & 9 & 24 & 4 & 11 & 0 & 0 & 2 & 5 \\
\hline Knee & 19 & 51 & 4 & 11 & 10 & 27 & 4 & 11 & 0 & 0 & 16 & 43 & 6 & 16 & 6 & 16 & 8 & 22 & 1 & 3 \\
\hline Thigh & 31 & 84 & 3 & 8 & 1 & 3 & 0 & 0 & 1 & 3 & 22 & 60 & 5 & 14 & 5 & 14 & 3 & 9 & 1 & 3 \\
\hline Hip & 24 & 65 & 7 & 19 & 4 & 11 & 1 & 3 & 1 & 3 & 17 & 46 & 8 & 22 & 6 & 16 & 4 & 11 & 0 & 0 \\
\hline
\end{tabular}




\section{Discussion}

Interventions focusing on foot health, particularly in nurses, are limited. Therefore, the electronic Foot Health Promoting Programme (FHPP) developed in this study is novel and fills this gap in the research knowledge. In this study, the electronic FHPP demonstrated effectiveness at a descriptive level only. The FHPP improved knowledge of foot self-care and improved foot health, but the changes were not statistically significant.

The present findings support the results of previous studies: knowledge of foot self-care can be influenced by education $[16,50,51]$. To achieve a greater change in the scores for knowledge of foot self-care, a face-to-face lecture and leaflets could provide supporting information to improve participants' knowledge levels. Changes in foot health may take longer to achieve. The post measurement (M1) was conducted 4 weeks after the intervention. This may be too short of a time to observe major changes in foot health. In the future, more measurement points (for example, at 12 and 24 weeks after the intervention) may reveal more variation in foot health.

The intervention was delivered in an online learning environment, where participants' learning and information-gaining strategies are crucial. The participants of this study may have been active or inactive in relation to managing their own health. We did not ask the participants about their level of motivation; therefore, no significant changes were observed. In addition, influencing individuals' motivation in an electronic learning environment is challenging. Therefore, the programme may benefit from elements of online or face-to-face practical demonstration [17] or telephone calls [50] to support participants in taking care of their feet.

Despite the lack of statistically significant results, in this research, a preventive foot-health intervention programme targeted at nurses was developed and tested. The results demonstrate the need to develop the content and delivery of the intervention further. With this development, the programme has the potential to prevent foot health problems among workers in occupational health care. The programme could be provided as part of routine health checks or targeted at those whose foot health needs special attention. If effective, the FHPP could promote nurses' foot health and general wellbeing, leading to improvements in their work ability, wellbeing and effectiveness at work. At the organisation level, the programme could make various units more efficient due to workers' improved foot health and general wellbeing. At the societal level, the programme would (at least partly) decrease sickness-related absences related to problems with the lower extremities.
Protecting the occupational health of nurses is important if we are to guarantee a trained workforce in clinical practice.

\section{Limitations}

Although the purpose of this study was to explore usability and provide preliminary evidence of potential effects, the study has some limitations that need to be discussed. First, the study design was a single group repeated-measures design. The study lacked a control group, but despite several attempts, it was not possible to recruit such a group. Without a control group, there is a chance that the results were affected by confounding factors such as lack of adherence or motivation towards foot self-care. Second, the sample size was limited. Only a small proportion of the total number of potential participants consented, despite several reminders and letters of encouragement. The reasons for this may include a lack of interest in foot health, a lack of time or a lack of motivation to participate. To confirm the effectiveness of the FHPP, a larger study that implements randomisation would be necessary. The generalisability of the results must be done with care. In terms of gender and professional background, the participants represented the averages for nurses working in specialised health care in Finland [52]. Third, the content of the FHPP focused on skin and toenail care, footwear and hosiery, foot structure and pain, and foot muscle strength. Comprehensive content would have been more informative, including for example, foot self-care to alleviate specific problems (such as corns, fissures or splay foot). However, the FHPP covered the core aspects of foot self-care and was supported by the expert panel.

The FHPP was developed systematically following evidence-based guidelines and recommendations on foot self-care. The content of the FHPP was reviewed by professionals in foot health care. The FHPP was delivered to each of the participants in a similar manner, and its content remained unchanged throughout the study. The participants were asked about the usability of the FHPP, and the majority believed that the content was useful and that the FHPP was easy to use. However, in the future, it would be beneficial to interview participants about their experiences of the FHPP to improve its technical functions and appearance. Moreover, user experiences of the content would be important to identify possible contextrelated development issues.

The instruments used in this study were all in Finnish and had been used in previous studies. The number of missing values was low, indicating that the instruments were easy to administer and that their content was understandable. The internal consistency of the S-FHAI (Kuder-Richardson coefficient 0.737) and the Foot Self- 


\author{
Care Knowledge Test (Kuder-Richardson coefficient \\ 0.617) was acceptable.
}

\section{Conclusions}

The Foot Health Promotion Programme is a promising tool to support nurses' foot self-care. The results provided preliminary evidence that it is possible to increase nurses' knowledge of foot self-care using an electronic web-based educational programme. However, further development of the educational programme is needed. In addition, the long-term or permanent increase in knowledge levels should be investigated using a followup design.

\section{Abbreviations}

FHPP: Foot Health Promoting Programme; MSD: Musculoskeletal disorder; TREND: Transparent Reporting of Evaluations with Nonrandomised Designs

\section{Acknowledgements}

None.

\section{Authors' contributions}

MS, JK, JP, RS and HL-K designed the study. MS collected the data and developed the intervention content. MS and JK analysed the data. MS and JP drafted the article. HL-K and RS critically revised the article for important intellectual content. All authors read and approved the final version of the manuscript.

\section{Funding}

Funding for this study was received from the Finnish Work Environment Fund (funding reference 116464) and Turku University Hospital special grantin-aid (funding reference 2017/13240). These funding bodies were not involved in and did not play any role in the design of the study; the collection, analysis, and interpretation of data; or writing of the manuscript.

\section{Availability of data and materials}

The datasets used and/or analysed during the current study are available from the corresponding author on reasonable request.

\section{Ethics approval and consent to participate}

Ethical approval was obtained, and all participants gave their written consent to participate in the study. The Ethics Committee at the University of Turku approved the study (code: ETMK 14/2015, 23.2.2015).

\section{Consent for publication}

Not applicable.

\section{Competing interests}

The authors declare that they have no competing interests.

\section{Author details}

'Department of Nursing Science, University of Turku, and Turku University Hospital, Turku, Finland. ${ }^{2}$ Department of Mathematics and Statistics, University of Turku, Turku, Finland. ${ }^{3}$ Department of Nursing Science, University of Turku, Turku, Finland. ${ }^{4}$ Department of Nursing Science, University of Turku, and Turku University Hospital, City of Turku, Welfare Division, Turku, Finland.

Received: 23 October 2019 Accepted: 6 April 2020

Published online: 19 April 2020

\section{References}

1. European Commission. Third EU Health Programme 2014-2020. 2014 https://ec.europa.eu/health/sites/health/files/programme/docs/ev_201411 04_co01_en.pdf. Accessed 17 Oct 2019.
2. WHO. Physical activity strategy for the WHO European Region 2016-2025 2015. www.euro.who.int/ data/assets/pdf file/0010/282961/65wd09e PhysicalActivityStrategy_150474.pdf. Accessed 17 Oct 2019.

3. López-López D, García-Mira R, Palomo-López P, et al. Attitude and knowledge about foot health: a spanish view. Rev Lat Am Enfermagem. 2017;25:e2855.

4. Stolt M, Suhonen R, Virolainen $P$, et al. Lower extremity musculoskeletal disorders in nurses: a narrative literature review. Scand J Public Health. 2016; 44:106-15.

5. López-López D, Becerro-de-Bengoa-Vallejo R, Losa-Iglesias ME, et al. Evaluation of foot health related quality of life in individuals with foot problems by gender: a cross-sectional comparative analysis study. BMJ Open. 2018:8:e023980.

6. Balanowski KR, Flynn LM. Effect of painful keratoses debridement on foot pain, balance and function in older adults. Gait Posture. 2005:22:302-7.

7. Taksande BA, Thote M, Jajoo UN. Knowledge, attitude, and practice of foot care in patients with diabetes at central rural India. J Fam Med Prim Care. 2017;6:284-7.

8. Semple R, Newcombe LW, Finlayson GL, et al. The FOOTSTEP selfmanagement foot care programme: are rheumatoid arthritis patients physically able to participate? Musculoskeletal Care. 2009;7:57-65.

9. D'Souza MS, Ruppert SD, Parahoo K, et al. Foot care behaviors among adults with type 2 diabetes. Prim Care Diabetes. 2016;10:442-51.

10. Stolt M, Miikkola M, Suhonen R, et al. Nurses' perceptions of their foot health: implications for occupational health care. Workplace Health Saf. 2017a;66:136-43.

11. Olson J, Hogan M, Pogach LM, et al. Foot care education and self management behaviors in diverse veterans with diabetes. Patient Prefer Adherence. 2009;3:45-50.

12. Matricciani $\mathrm{L}$, Jones $\mathrm{S}$. Who cares about foot care? Barriers and enablers of foot self-care practices among non-institutionalized older adults diagnosed with diabetes: an integrative review. Diabetes Educ. 2015:41:106-17.

13. Stolt $M$, Gattinger $H$, Boström $C$, et al. Foot health educational interventions for patients and healthcare professionals: A scoping review. Health Educ J. 2019. https://doi.org/10.1177/0017896919888952.

14. Ahmad Sharoni SK, Abdul Rahman H, Minhat HS, et al. The effects of selfefficacy enhancing program on foot self-care behaviour of older adults with diabetes: a randomised controlled trial in elderly care facility, Peninsular Malaysia. PLoS One. 2018;13:e0192417.

15. Ahmad Sharoni SK, Minhat HS, Mohd Zulkefli NA, et al. Health education programmes to improve foot self-care practices and foot problems among older people with diabetes: a systematic review. Int J Older People Nursing. 2016;11:214-39.

16. Baba M, Duff J, Foley L, et al. A comparison of two methods of foot health education: the Fremantle diabetes study phase II. Prim Care Diabetes. 2015;9: 155-62.

17. Monami M, Zannoni S, Gaias M, et al. Effects of a short educational program for the prevention of foot ulcers in high-risk patients: a randomized controlled trial. Int J Endocrinol. 2015. https://doi.org/10.1155/2015/615680.

18. Seyyedrasooli A, Parvan $K$, Valizadeh $L$, et al. Self-efficacy in foot-care and effect of training: a single-blinded randomized controlled clinical trial. Int J Community Based Nurs Midwifery. 2015;3:141-9.

19. Adarmouch $L$, Elyacoubi $A$, Dahmash $L$, et al. Short-term effectiveness of a culturally tailored educational intervention on foot self-care among type 2 diabetes patients in Morocco. J Clin Transl Endocrinol. 2017:7:54-9.

20. Omote $\mathrm{S}$, Watanabe A, Hiramatsu $\mathrm{T}$, et al. A foot-care program to facilitate self-care by the elderly: a non-randomized intervention study. BMC Res Notes. 2017;10:586.

21. Vatankhah N, Khamseh ME, Noudeh YJ, et al. The effectiveness of foot care education on people with type 2 diabetes in Tehran, Iran. Prim Care Diabetes. 2009;3:73-7.

22. Hassan ZM. Mobile phone text messaging to improve knowledge and practice of diabetic foot care in a developing country: feasibility and outcomes. Int J Nurs Pract. 2017. https://doi.org/10.1111/ijn.12546.

23. OECD. Health at Glance. 2011. http://www.oecd-ilibrary.org/social-issuesmigration-health/health-at-a-glance-2011_health glance-2011-en. Accessed 17 Oct 2019.

24. Bureau of Labor Statistics. Labor force statistics from the current population survey. 2003. https://www.bls.gov/cps/cps_aa2003.htm. Accessed 17 Oct 2019.

25. EASHW. OSH in figures - Work-related musculoskeletal disorders in the EU Facts and figures: European Agency for Safety and Health at Work; 2010. 
https://osha.europa.eu/en/publications/reports/TERO09009ENC. Accessed 17 Oct 2019.

26. Welton JM, Decker M, Adam J, et al. How far do nurses walk? Medsurg Nurs. 2006;15:213-6.

27. Anderson J, Williams AE, Nester CJ. A narrative review of musculoskeletal problems of the lower extremity and back associated with the interface between occupational tasks, feet, footwear and flooring. Musculoskeletal Care. 2017; 15:3043-15.

28. Anderson J, Williams AE, Nester C. An explorative qualitative study to determine the footwear needs of workers in standing environments. J Foot Ankle Res. 2017;10:41. https://doi.org/10.1186/s13047-017-0223-4.

29. Smith DR, Sato M, Miyajima T, et al. Musculoskeletal disorders self-reported by female nursing students in Central Japan: a complete cross-sectional survey. Int J Nurs Stud. 2003;40:725-9.

30. Trinkoff AM, Lipscomb JA, Geiger-Brown J, et al. Perceived physical demands and reported musculoskeletal problems in registered nurses. Am J Prev Med. 2003;24:270-5.

31. Tüchsen F, Krause N, Hannerz $H$, et al. Standing at work and varicose veins. Scand J Work Environ Health. 2000;26:414-20.

32. $\mathrm{IOSH}=$ Institute of Occupational Safety and Health. Health hazard surveillance of female worker focusing on medical professionals, vol. 92: IOSH; 2003. p. M-345.

33. Andersen LL, Clausen T, Mortensen OS, et al. A prospective cohort study on musculoskeletal risk factors for long-term sickness absence among healthcare workers in eldercare. Int Arch Occup Environ Health. 2012;85:615-22.

34. Nealy R, McCaskill C, Conaway MR, et al. The aching feet of nurses: an exploratory study. Medsurg Nurs. 2012;21:354-9.

35. Chiu M-C, Wang M-JJ. Professional footwear evaluation for clinical nurses. Appl Ergon. 2007;38:133-41.

36. Lee J-E, Kin S-L, Jung H-S, et al. Participatory action oriented training for hospital nurses (PAOTHN) program to prevent musculoskeletal disorders. J Occup Health. 2009;51:370-6.

37. Lin HJ, Black TR, Shah SM, et al. Evaluating repeated patient handling injuries following the implementation of a multi-factor ergonomic intervention programme among health care workers. J Saf Res. 2011;42: 185-91.

38. Szeto GP, Law KY, Lee $E$, et al. Multifaceted ergonomic intervention programme for community nurses: pilot study. J Adv Nurs. 2010;66:1022-34.

39. Tullar JM, Brewer S, Amick BC, et al. Occupational safety and health interventions to reduce musculoskeletal symptoms in the health care sector. J Occup Rehabil. 2010;20:199-219.

40. Collins JW, Wolf L, Bell J, et al. An evaluation of a "best practice" musculoskeletal injury prevention program in nursing homes. Inj Prev. 2004; 10:206-11.

41. Nelson A, Matz M, Chen F, et al. Development and evaluation of a multifaceted ergonomics program to prevent injuries associated with patient handling tasks. Int J Nurs Stud. 2006;43:717-33.

42. Des Jarlais DC, Lyles C, Crepaz N, the TREND group. Improving the reporting quality of nonrandomized evaluations of behavioral and public health interventions: The TREND statement. Am J Public Health. 2004;94:361-6.

43. Stolt M, Suhonen R, Puukka $\mathrm{P}$, et al. Nurses' knowledge of foot care in the context of home care: a cross-sectional correlational survey study. J Clin Nurs. 2015;24:2916-25.

44. Stolt M, Suhonen R, Puukka P, et al. Development process and psychometric testing of foot health assessment instrument. J Clin Nurs. 2013;22:1310-21.

45. Tuomi K, Ilmarinen J, Jahkola M, et al. Work ability index. In: Occupational health care. 2nd revised ed. Helsinki: Finnish Institute of Occupational Health; 2006.

46. Stolt M, Suhonen R, Kielo E, et al. Foot health of nurses - A cross-sectional study. Int J Nurs Pract. 2017b. https://doi.org/10.1111/ijn.12560.

47. Graneheim UH, Lundman B. Qualitative content analysis in nursing research: concepts, procedures and measures to achieve trustworthiness. Nurs Educ Today. 2004;24:105-12.

48. ALLEA. The european code of conduct for research integrity. 2017. https:// allea.org/code-of-conduct/. Accessed 17 Oct 2019.

49. Finnish Advisory Board on Research Integrity. Responsible conduct of research and procedures for handling allegations of misconduct in Finland. 2012. https://www.tenk.fi/en. Accessed 17 Oct 2019.

50. Fan L, Sidani S, Cooper-Brathwaite A, et al. Feasibility, acceptability and effects of a foot self-care educational intervention on minor foot problems in adult patients with diabetes at low risk for foot ulceration: a pilot study. Can J Diabetes. 2013;37:195-201.

51. Rahaman HS, Jyotsna VP, Sreenivas $V$, et al. Effectiveness of a patient education module on diabetic foot Care in Outpatient Setting: an openlabel randomized controlled study. Indian J Endocrinol Metab. 2018;22:74-8.

52. National Institute for Health and Welfare. Health care and social welfare personnel 2013. Statistical report. 2015. http://urn.fi/URN:NBN:fi-fe2015121 023438. Accessed 17 Oct 2019.

\section{Publisher's Note}

Springer Nature remains neutral with regard to jurisdictional claims in published maps and institutional affiliations.
Ready to submit your research? Choose BMC and benefit from:

- fast, convenient online submission

- thorough peer review by experienced researchers in your field

- rapid publication on acceptance

- support for research data, including large and complex data types

- gold Open Access which fosters wider collaboration and increased citations

- maximum visibility for your research: over $100 \mathrm{M}$ website views per year

At BMC, research is always in progress.

Learn more biomedcentral.com/submissions 